\title{
Analysis of displaced acetabular fractures in adults treated with open reduction and internal fixation
}

\author{
Khazi Syed Asif Hussain*, Nageswara Rao Kancherla, Sandeep Kumar Kanugula, \\ Chandrasekhar Patnala
}

Department of Orthopedics, Nizams Institute of Medical Sciences, Hyderabad, Telangana, India

Received: 09 August 2016

Accepted: 13 August 2016

\author{
*Correspondence: \\ Dr. Khazi Syed Asif Hussain, \\ E-mail: asifks@yahoo.com
}

Copyright: ( ) the author(s), publisher and licensee Medip Academy. This is an open-access article distributed under the terms of the Creative Commons Attribution Non-Commercial License, which permits unrestricted non-commercial use, distribution, and reproduction in any medium, provided the original work is properly cited.

\section{ABSTRACT}

Background: The incidence of acetabular fractures is increasing worldwide at a rapid rate due to increase in rail and road traffic accidents and high velocity injuries. The incidence of acetabular fractures is increasing worldwide at a rapid rate due to increase in rail and road traffic accidents and high velocity injuries.

Methods: 30 patients aged between 18 to 60 years with closed displaced acetabular fractures were included into the study. A single surgical approach such as the Kocher-Langenbeck, the ilioinguinal, and the extended iliofemoral approach was selected depending on the type of fracture, with the expectation that the fracture reduction and fixation can be completely performed through the one approach.

Results: Out of the 30 patients, 12 patients were between the 21-30 age group and 10 were between 31-40 age group with most of them being males involved in road traffic accidents. Predominance of right side was seen in 22 ( 73 , $33 \%)$ and $8(26.66 \%)$ persons had left sided fractures. Posterior wall fractures were seen in 5 cases while transverse was seen in 4 cases. Combinations of both were seen in 8 patients. The outcomes were excellent in more than $56 \%$ of the cases and good in more than $30 \%$ of them.

Conclusions: Present study needs further follow up for better understanding of long term results.

Keywords: Acetabular fractures, Open reduction, Internal fixation, Kocher-Langenbeck approach

\section{INTRODUCTION}

The incidence of acetabular fractures is increasing worldwide at a rapid rate due to increase in rail and road traffic accidents and high velocity injuries. Other types of injuries like fall from height, mine accidents also contribute to the increase of incidence of these injuries. These fractures are often associated with other lifethreatening injuries.

Acetabular fractures occur when the head of the femur is driven into the pelvis, either by a blow on the side of hip or by a blow on the front of knee with the hip in flexion and abduction (Dash board injury). The fracture pattern depends on the position of hip, direction of impact, magnitude of impact, and strength of the bone at the time of injury. The treatment of acetabular fractures is a complex area of orthopaedics that is being continually refined. There have been many changes in the recommended treatment modalities over time as the understanding of acetabular anatomy and fracture patterns developed which acts as a first step in decision making for the mode of treatment. ${ }^{1,2}$

Although certain fracture patterns may not require surgery to have a satisfactory outcome, in general, those with hip instability, hip incongruity, or fracture displacement in the superior weight-bearing area of the acetabulum should be managed with open reduction and internal fixation. Acetabular fractures are many times associated with life threatening multiple traumatic injuries which may often be missed. ${ }^{3}$ Fractures of 
extremities, head injuries, chest, abdomen and pelvic ring injuries are many times associated with acetabular fractures. ${ }^{4}$ Computed tomography has proved invaluable in management of acetabular fractures management. 3D reconstruction helps in further defining the fracture pattern, especially for inexperienced surgeons. ${ }^{5}$ There had been a number of studies in the past highlighting the outcomes of open reduction and internal fixation of acetabular fractures. The aim of our present study is to report the short term and long term outcomes of surgically fixed acetabular fractures.

\section{METHODS}

This prospective study was conducted by the Department of Orthopedics at Nizams Institute of Medical Sciences during the period January 2014 to September 2015. 30 patients aged between 18 to 60 years with closed displaced acetabular fractures according to Judet and Letournel classification were included in the study.

Patients with compound fractures, skeletally immature patients, those with pathological fractures and patients with medical contraindications for surgery were excluded from the study. On admission, demographic details pf the patients were noted along with the social background. Clinical evaluation such as nature of the fracture, other comorbid conditions associated injuries and systemic injuries were also noted. Anteroposterior and 45 degrees oblique view (Judet views) of the pelvis were obtained for all patients following admission. Computerized tomography with $3 \mathrm{D}$ reconstruction scans were performed in all cases.

Before planning for fixation of acetabular fracture, a proper preoperative planning is very much essential. Timing of surgery is very crucial for good outcome. Acetabular fixation done before 3 weeks of injury is likely to give good anatomical reduction and clinical outcome. No single approach is ideal for fixation of all types of fractures. A single surgical approach is generally selected with the expectation that the fracture reduction and fixation can be completely performed through the one approach. The most commonly used surgical approaches to the acetabulum are the KocherLangenbeck, the ilioinguinal, and the extended iliofemoral approach.

The acetabular fracture is fixed with implants with $4 \mathrm{~mm}$ cancellous screws (fully threaded, partially threaded) 3.5 $\mathrm{mm}$ cortical screws, $3.5 \mathrm{~mm}$ reconstruction plate. Reconstruction plates are routinely used to buttress the posterior wall fractures and also for anterior and posterior column fractures. Postoperatively, patients were maintained on intra venous antibiotics for at least 5days. Early mobilization was stressed and patients were encouraged to sit up within the first 24-48 hours following surgery after the removal of the drain. However, weight bearing is not allowed for 10-12 weeks. In the case of an extended ilio-femoral approach or a trochanteric osteotomy, active abduction is avoided for 6 8 weeks.

All patients were reviewed after 6 weeks postoperatively, for active and active assisted hip ROM exercises. Again reviewed at 3 months postoperatively and gradual weight bearing was started. During the third month, depending on radio graphic evidence of healing, the patient is allowed to progress to full weight bearing as tolerated.

Complications if any were noted. Modified Merle d“ Aubigne scoring system was used to measure the functional outcome and Matta's criteria used for evaluating accuracy of reduction.

\section{RESULTS}

Out of the 30 patients, 12 patients were between the 21 30 age group and 10 were between $31-40$ age group, asserting that this type of accidents were associated with the age group at risk for road traffic accidents. The average age of incidence was 32.5 years. The age for the youngest patients was 18 years and that of the eldest patient was 60 years (Figure 1).

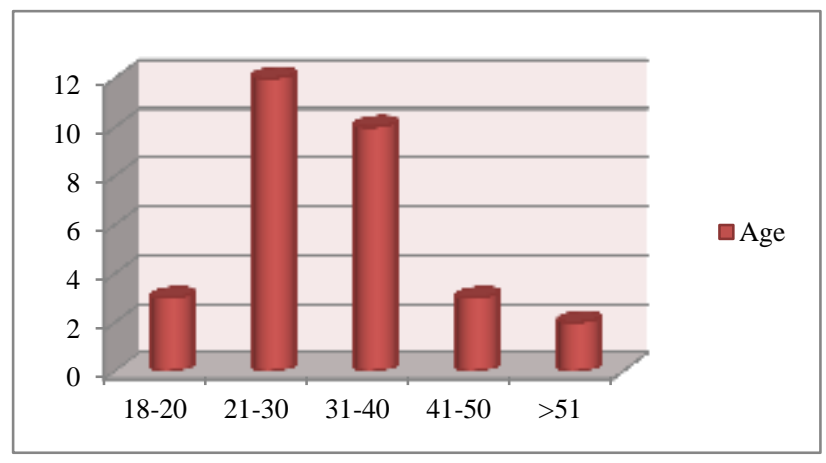

Figure 1: Age wise distribution of patients.

Table1: Type of fracture.

\begin{tabular}{|ll|}
\hline Type of fracture & Number of cases \\
\hline Posterior wall & 5 \\
\hline Posterior column & 2 \\
\hline Anterior wall & 0 \\
\hline Anterior column & 0 \\
\hline Transverse & 4 \\
\hline T Shaped & 2 \\
\hline Transverse + Posterior wall & 8 \\
\hline Posterior column + Posterior wall & 7 \\
\hline $\begin{array}{l}\text { Anterior column + Posterior hemi } \\
\text { transverse }\end{array}$ & 0 \\
\hline Both column & 2 \\
\hline Total & 30 \\
\hline
\end{tabular}

Males were more common amongst the ones to be affected $(90 \%)$, probably due to their work style rather than the women $(10 \%)$. RTA was the most common 
cause of fractures with $25(83.33 \%)$ cases and $5(16.66 \%)$ were due to fall from height.

Predominance of right side was seen in $22(73,33 \%)$ and $8(26.66 \%)$ persons had left sided fractures. Posterior wall fractures were seen in 5 cases while transverse was seen in 4 cases. A combination of both was seen in 8 patients (Table 1). Out of the 19 patients who had dislocation, 14 reeduced within 12 hours while out of the 11 without dislocation, 5 patients showed reduction within 12 hours (Figure 2-4).

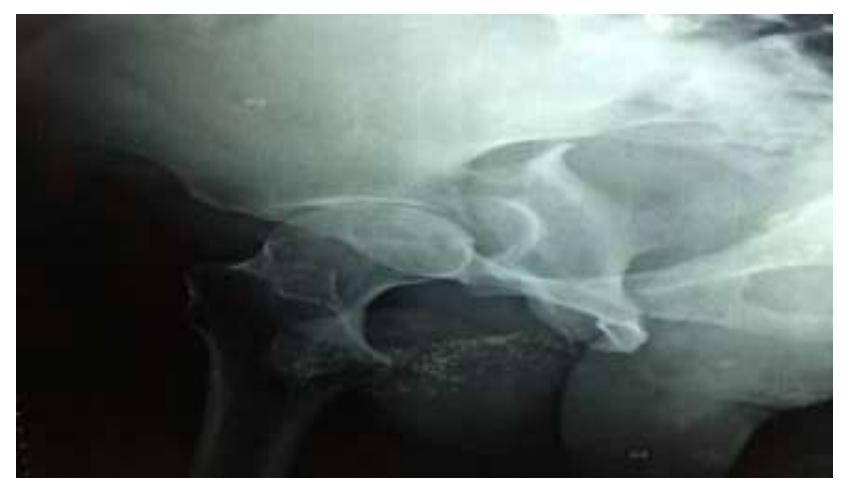

Figure 2: Before surgery.

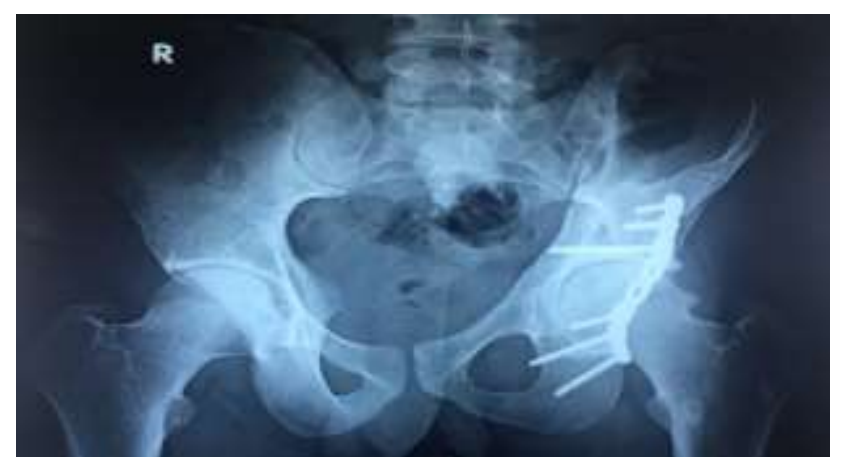

Figure 3: After surgery.

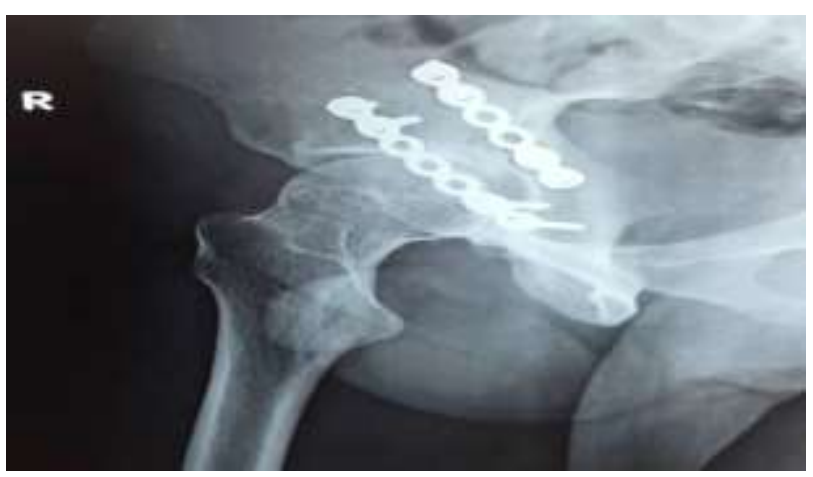

Figure 4: After surgery.

$22(73.33 \%)$ patients had associated injuries of which the most common was Ipsilateral extremity injury with 14 $(63.63 \%)$ cases (Figure 2-5). Post op, there were hardly any complications, except in one patient who developed infection and was treated accordingly.

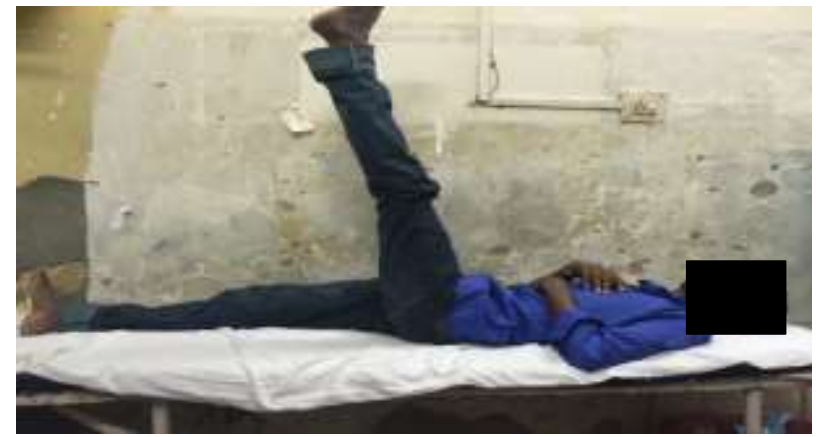

Figure 5: Mobility after surgery.

18 patients had anatomic $(0-1 \mathrm{~mm})$ reduction in fracture according to the Matta's criteria. 17 of them had excellent outcomes according to the modified Merle D'Aubigne and Postel Clinical Grading system, while 9 of them had good results as was the case with the Matta Radiological score (Table 2).

Table 2: Outcomes of surgery by different criteria.

\begin{tabular}{|lll|}
\hline Outcome & $\begin{array}{l}\text { No of } \\
\text { patients }\end{array}$ & Percentage \\
\hline $\begin{array}{l}\text { Matta's Criteria - } \\
\text { reduction of fracture }\end{array}$ & & \\
Anatomic (0-1mm) & 18 & $60 \%$ \\
Imperfect (2-3mm) & 10 & $33.33 \%$ \\
Poor (0.3mm) & 2 & $6.67 \%$ \\
\hline Modified Merle & & \\
D'Aubigne and Postel & & \\
Clinical Grading system & & \\
Excellent & 17 & $56.67 \%$ \\
Good & 9 & $30 \%$ \\
Fair & 2 & $6.67 \%$ \\
Poor & 2 & $6.67 \%$ \\
\hline Matta Radiological & & \\
Scoring system & & \\
Excellent & 17 & $56.67 \%$ \\
Good & 9 & $30 \%$ \\
Fair & 2 & $6.67 \%$ \\
Poor & 2 & $6.67 \%$ \\
\hline
\end{tabular}

\section{DISCUSSION}

Acetabular fractures are severe injuries and they can be a complex surgical problem. The greatest contribution towards a better understanding of acetabular fractures, their classification, the mechanism of the fracture, and surgical treatment was given by Judet and Letournel. ${ }^{6}$

Yet, they have the potential for a poor outcome regardless of the treatment method. The contributing factors may include an imperfect reduction, osteochondral defects in either the acetabulum or the femur at the time of injury, osteoarthritis, AVN of the femoral head, heterotropic ossification, sciatic nerve injury and infection. ${ }^{7}$ The fracture pattern, marginal impaction and residual displacement of $>2 \mathrm{~mm}$ are known to be associated with 
the development of arthritis. Non operative treatment for acetabular fractures has become a rarity. Open reduction and internal fixation is now a common treatment of choice as it enables an early mobilization of the patient.

The main cause of an acetabular fracture is road traffic accident. In our study, RTA accounted for $83.3 \%$ of the cases, with the rest being due to fall from height. This was similar to a retrospective study by Almeida et al wherein 60 out of 76 cases were due to RTA and a metaanalysis by Giannoudis et al where the association of RTA was seen in over $80 \%$ of the cases. ${ }^{8,9}$

The most common age group in our study to have these types of fractures was between 21-40 years, with males being the predominant gender affected. The average age was 32.5 years. According to Giannoudis et al, the average age of the patients affected was 38.6 years and most of them $(69.4 \%)$ were males. In yet other studies by Triantaphillopoulos et al, Moed et al and Kumar et al, the average age was 34.6years, 37years, and 39.5 years. $^{9-12}$ The type of fractures observed in our study was posterior wall with transverse fractures $(26.6 \%)$, posterior wall and column $(23.33 \%)$ posterior wall $(16.6 \%)$, transverse $(13.3 \%)$, isolated posterior column fractures $(6.6 \%), \mathrm{T}$ shaped fractures $(6.6 \%)$ and both column fractures $(6.6 \%)$.

The most common complication, with an incidence of 20$50 \%$, found in literature was traumatic arthritis of the hip. ${ }^{11,13,16-18}$ None of our patients developed this complication. It was probably due to the fact that traumatic arthritis develops after a long time and in our case the follow up period was short. The only complication observed in our study was infection and that too was seen only in one patient. Another complication common was avascular necrosis (AVN). ${ }^{11,13,19-22}$ The rate of AVN has estimated to be between 3-10\%, but in cases with posterior dislocation of hip, the rate is higher. We had no case of AVN in our study, which could be due to the short follow-up period.

The quality of reduction was found to be excellent in $56.67 \%$ and good in $30.33 \%$. In a similar study, Matta et $\mathrm{al}^{13}$ reported a perfect anatomical reduction in $64 \%$ of the cases while Stockle et al reported $79.5 \% .{ }^{14}$ Moed et al found that long-term good-to excellent results can be expected after anatomical reduction which they observed to be $89 \% .{ }^{11}$ On the other hand, Khadrawe et al achieved complete anatomical reduction only in $32.7 \%$ of the cases. $^{15}$

According to Merle D'Aubigne score, excellent resultswere seen in $56.67 \%$ of the cases which was very similar to the study by Moed et al, who found excellent results in $55 \%$ of the cases. $40 \%, 38.1 \%$ and $34 \%$ excellent results were found by Petsetoidis et al, Elmali et al and Edbaheim et al respectively. ${ }^{23-25}$ Most of present patients were encouraged to sit on the bed and do knee range of movements within 36 hours of the surgery and allowed to walk by 6 weeks after the surgery. In patients with poor bone quality and/or associated fractures, mobilization was delayed. The main limitation in present study was the short duration of the follow up. Early failures were attributed to imperfect reductions or biological failures such as infection or avascular necrosis, while late failures were due to the inevitable development of osteoarthritis. The first peak occurred within the first three years while the second peak occurred at $10-15$ years follow-up. Therefore to observe the long term outcomes of this surgery, a follow-up of at least 10 years need to be maintained.

\section{CONCLUSION}

The incidence of acetabular fractures is increasing, owing to the increased frequency of road traffic accidents and high velocity injuries with younger males being the most affected. Incidence of heterotopic ossification can be reduced with good surgical technique; indomethacin and irradiation may not be required post operatively. In majority of cases there is correlation between the reduction of fracture and clinical and radiological outcomes. Our study needs further follow up for better understanding of long term results

Funding: No funding sources

Conflict of interest: None declared

Ethical approval: The study was approved by the institutional ethics committee

\section{REFERENCES}

1. Kebaish AS, Roy A, Rennie WJ. Displaced acetabular fractures: long term follow-up. Trauma 1991;31(11):1539-42.

2. Anizar-Faizi A, Hisam A, Sudhagar KP, Moganadass M, Suresh C. Outcome of surgical treatment for displaced acetabular fractures. Malays Orthop J. 2014;8(3):1-6.

3. Porter SE, Schroeder AC, Dzugan SS, Graves ML, Zhang L, Russell GV. Acetabular fracture patterns and their associated injuries. J Orthop Trauma. 2008;22(3):165-70.

4. Milenković S, Saveski J, Radenković M, Vidić G, Trajkovska N. Surgical treatment of displaced acetabular fractures. Srp Arh Celok Lek. 2011;139(7-8):496-500

5. Durkee NJ, Jacobson J, Jamadar D, Karunakar MA, Morag Y, Hayes C. Classification of common acetabular fractures: radiographic and CT appearances. AJR Am J Roentgenol. 2006;187:91525.

6. Letournel E. Acetabulum fractures: classification and management. Clin Orthop Relat Res. 1980;(151):81-106.

7. Briffa N, Pearce R, Hill AM, Bircher M. Outcomes of acetabular fracture fixation with ten years' follow-up. J Bone Joint Surg Br. 2011;93:229-36. 
8. Almeida AGI de, Garrido CA, Amaral LEV, Vargas LFL. Prospective study on seventy-six cases of fractured acetabulum with surgical treatment. Rev Bras Orthop. 2011;46(5):520-5.

9. Giannoudis PV, Grotz MRW, Papakostidis C, Dinopoulos H. Operative treatment of displaced fractures of the acetabulum - A meta-analysis. J Bone Joint Surg Br. 2005;87(1):2-9.

10. Triantaphillopoulos PG, Panagiotis T, Panagiotopoulos EC, Elias P, Mousafiris C, Constantinos $\mathrm{M}$, et al. Long-term results in surgically treated acetabular fractures through the posterior approaches. J Trauma. 2007;62(2):378-82.

11. Moed BR, Paul HY, Gruson KI. Functional outcomes of acetabular fractures. J Bone Jt Surg. 2003;85(10):1879-83.

12. Kumar A, Shah NA, Kershaw SA, Clayson AD. Operative management of acetabular fractures. Injury. 2005;36(5):605-12.

13. Matta JM. Fractures of the acetabulum: accuracy of reduction and clinical results in patients managed operatively within three weeks after the injury. J Bone Joint Surg Am. 1996;78(11):1632-45.

14. Stöckle U, Hoffmann R, Nittinger M, Südkamp NP, Haas NP. Screw fixation of acetabular fractures. Int Orthop. 2000;24(3):143-7.

15. El-khadrawe TA, Hammad AS, Hassaan AE. Indicators of outcome after internal fixation of complex acetabular fractures. Alex J Med. 2012;48(2):99-107.

16. Olson SA, Matta JM. The computerized tomography subchondral arc: a new method of assessing acetabular articular continuity after fracture (a preliminary report). J Orthop Trauma. 1993;7(5):402-13.

17. Mayo KA. Open reduction and internal fixation of fractures of the acetabulum. Results in 163 fractures. Clin Orthop. 1994;(305):31-7.
18. Wright R, Barrett K, Christie MJ, Johnson KD. Acetabular fractures: long-term follow-up of open reduction and internal fixation. J Orthop Trauma. 1994;8(5):397-403.

19. Jawad MU, Haleem AA, Scully SP. In brief: Ficat classification: avascular necrosis of the femoral head. Clin Orthop. 2012;470(9):2636-9.

20. Öner AY, Aggunlu L, Akpek S, Celik A, Le Roux $\mathrm{P}$, Tali T, et al. Staging of hip avascular necrosis: is there a need for DWI? Acta Radiol Stockh Swed 1987. 2011;52(1):111-4.

21. Baksi DP. Avascular necrosis. Indian J Orthop. 2002;36(4):267.

22. Schmitt-Sody M, Kirchhoff C, Mayer W, Goebel M, Jansson V. Avascular necrosis of the femoral head: inter- and intraobserver variations of Ficat and ARCO classifications. Int Orthop. 2008;32(3):2837.

23. Petsatodis G, Antonarakos P, Chalidis B, Papadopoulos P, Christoforidis J, Pournaras J. Surgically treated acetabular fractures via a single posterior approach with a follow-up of 2-10 years. Injury. 2007;38(3):334-43.

24. Ebraheim NA, Patil V, Liu J, Sanford CG, Haman SP. Reconstruction of comminuted posterior wall fractures using the buttress technique: a review of 32 fractures. Int Orthop. 2006;31(5):671-5.

25. Elmali N, Ertem K, Inan M, Ayan I, Denizhan Y. Clinical and radiologic results of surgically-treated acetabular fractures. Acta Orthop Traumatol Turc. 2004;37(2):97-101.

Cite this article as: Hussain KSA, Kancherla NR, Kanugula SK, Patnala C. Analysis of displaced acetabular fractures in adults treated with open reduction and internal fixation. Int $\mathbf{J}$ Res Orthop 2016;2:99-103. 